\title{
Experiences and Participatory Tools for Evaluation of Sustainability of Local Development Projects
}

\author{
Manrique, Silvina ${ }^{1}$ and Franco, Judith.
}

\begin{abstract}
.
The Sustainability measuring is the strongest conducting force for the discussion of Sustainable Development (SD). A reliable measuring tool is a prerequisite for the assessment sustainability the processes, alternatives or systems. In Salta, Argentina, the bioenergy systems (energy systems based on biomass) could be implemented but it is necessary to define the baseline, in order to be able to monitor changes of the system as a whole. We build a simple and replicable methodology to estimate the level of sustainability - from a framework locally and participating defined- of the Central Region (system or unit of analysis), and test how this level of sustainability could improve or worsen from the implementation of an bioenergy project. By means of a multidimensional analysis and the calculation of indexes, a current image diagnosis was obtained. This image was observed then in the potential future evolution, if bioenergy systems are implemented in the zone. The failings and the imbalances of the system are clearly identified, and therefore, allow focus towards the dimensions and variables that need to implement policies and corrective instruments. The methodology developed could be used to test other projects for the region or to be retrofitted with new variables in other regions.
\end{abstract}

\section{Introduction}

United Nations popularized the term sustainable development in the report "Our Common Future" (1987: 43) or Brundtland Report (WCED, 1987). This reports recognized as the first global and institutionalized attempt of treating the economic welfare, the environmental protection and the social justice simultaneously, taken as the three dimensions of sustainable development (Tijmes and Luijf, 1995; Lumley and Armstrong, 2004). This report becomes a point the reference for every debate on sustainable development (SD)and the search for redefinition of the concept (May and Brennan, 2006; Holden and Linnerud, 2007).

Actually, in despite of the differences in opinion on the subject, there is an agreement that SD is not a fixed condition or a final state, but it is a dynamic process (Mog, 2004). Although nobody can know how a sustainable society will be in the future, it is clear that some human activities, if not stopped or changed, will not contribute to the achievements of that society. Kemmler and Spreng (2007) mention that this dynamic process must be continuously evaluated: the system's tendencies and the desired goals must be evaluated and corrected accordingly. George (1999) states that its measurement is indispensable for the operation of this concept: it should be possible to measure whether a type of development is sustainable. This requirement was recognized in the Agenda 21 which states that the sustainable development indicators need to be developed in order to provide solid bases for the decision making at all levels. The

${ }^{1}$ Non Conventional Energy Resources Investigation Institute (INENCO) of National University of Salta (UNSa) and National Council of Scientific and Technical Research (CONICET), Av. Bolivia 5150, A4400FVY, Salta, Argentina. Phone: +54 93874255424. 
indicators facilitate the orientation in a complex world by condensing great amounts of information in recognizable patterns (Bossel, 1999; Buchholz et al., 2009). For this, it is necessary to identify and consider each significant aspect of the environment and each important component that contributes to the quality of life. On the other hand, the establishing indicators show a greater sensibility if they refer individually to each component that has been identified as important, since the added indicators can hide the weight of some of the integrating factors and show adverse results (George, 1999). In addition, it is necessary to know the impact each of these components has on the quality of human life and the environment in the case they are modified, since in some cases, a small modification may not be acceptable.

The construction of the concept of sustainability from an energy point of view requires taking into account aspects such as: prevention and reversal of environmental impacts of the system; security in the supply and decrease in energy dependency (especially of dirty sources); coverage and the entire population's equitable access to resources and services of energy; population's democratic participation in the decision making processes about politics and energy projects. The energy sustainability demands consideration and satisfaction of the society's needs, not only of physical survival but also economics, social, political, cultural and environmental needs for a dignified life (Begic and Afgan, 2007; Buchholz et al., 2009). The type of energy used, the way it is produced, the access and distribution mechanisms and the benefits determine the type of development and the levels of sustainability possible to achieve (Takada et al., 2000).

The biomass, as a source of renewable energy, but also as locally applicable strategic tool, could contribute to SD, which should be evaluated in each case. The northwest of Argentina, Salta particularly, it has been identified as a territory or region with a wide range of biomass resources. We work identifying bioenergy projects in this area, but also identified in a participatory manner, what was the perception of local sustainability, how we could quantify, and estimate how bioenergy projects could impact local sustainability. We build a simple and replicable methodology to estimate the level of sustainability from a framework locally and participating defined- of the Lerma Valley (system or unit of analysis), and test how this level of sustainability could improve or worsen from the implementation of an bioenergy project.

\section{Materials and Methods}

\subsection{Study area}

Lerma Valley, in the center of the Salta province, Argentina, is composed of 13 municipalities. $53 \%$ of the population is concentrated in the Valley (about 530.000 inhabitants). Excluding the capital, $70 \%$ of the Valley population corresponds to urban population and $30 \%$ to rural population. The total surface is approximately 500,500 ha and the average altitude is 1,000 m.a.s.l. The Valley is a territorial unit of great importance for the province because of fertile soils, moderate climate and water availability. The cultivation of tobacco is mainly developed. 


\subsection{Bioenergy System selection}

It was assumed that the local energy demand had priorities from the standpoint of SD. It was necessary to reduce the possible universe, concentrate efforts, optimize scarce resources (time, money, personal) and define specific bioenergy systems that could be developed in the Valley. We considered different criteria for this selection: the amount of the resource in surface unit; the periodicity, frequency or resource generation rate by unit of time; the resource scattering; visible local impact (contamination, emissions, residue, social aspects or other factors); current uses or established uses of the resource like for example, fertilizer, forage, crafts, etc.; legal and physical accessibility (includes ownership, legal restrictions, orography -difficult terrain situations-); perception and interest of biomass use or social acceptance; perspective of the future existence of the resource in quality and quantity (probability that the source of generation of the resource will continue to exist, either by political, legal, economical, financial, cultural, or other backup). All these aspects allow the selection of three bioenergetics systems described in greater detail in Manrique et al. (2014): agricultural residues (tobacco mainly) to replace fossil fuels in the production cycles (heating purposes); biogas from municipal solid waste (MSW) arranged in a regional landfill for power generation (electricity from an internal combustion engine); shrubs and bushes management (Acacias mainly) for heating purposes.

\subsection{Data collection}

The unit of analysis (Lerma Valley) was worked in two situations: a) current diagnosis on the level of estimated SD; and b) potential future status after the implementation of bioenergy systems.

The basic information was obtained from two techniques: informal interviews and the survey of selected cases. The first included interviews with 38 key informants from the five sectors: i) governments (mayors and/or secretaries of government); ii) companies of tobacco; iii) associations (Chambers of local and municipal tobacco; Tobacco Mutual of Salta; Irrigation Consortia, Associations of Small Producers of the Valley, craft associations); iv) producers (tobacco and horticultural); v) people (located in positions of access to the population: health care workers, teachers, nurses, community leaders and merchants). The academic-scientific sector, which was not consulted in interviews, was incorporated in subsequent analyzes by studying secondary information (reports, papers, promotional material, etc.).This stage was useful to get an overview of the technical and economic characteristics of the different agricultural systems, the predominant types of businesses and relationships, and perception of the context of local actors. Beyond seeking a definition of SD, we sought to identify how this concept could be made operational in practice, according to detect how its meaning it was perceived. At these actors were also consulted about their assessment of importance of the four dimensions of sustainability considered: Economic (E), Social (S), Environmental (A) and Organizational-Institutional (I) (on a scale of 1-100 from low to high importance). Responses were averaged. Secondary and primary information obtained in the interviews, provided the basis for the design and preparation of surveys, insofar as it allowed the definition of indicators to assess the "level" of SD of the Valley, and therefore oriented 
the preparation of the survey.

For the second step, a total number of 100 field surveys were made, defined from cases selected according to criteria defined. Four categories of producers were considered, depending on the worked surface: from 0 to 5 ha, from 5.1 to 15 ha, from 15.1 to 50 ha and more than 50 ha. The surveys were divided equally among all municipalities in the Valle (department capital excluded). It is noteworthy that although sought to obtain the answers to the questions identified in the survey, the field work was flexible and entertaining dialogues were held with the producers, making valuable additional information. It was obtained the opinion of a percentage of the population without statistical purposes.

\subsection{SD level estimation for the Valley}

The methodology used for the generation of Sustainable Development Index (SDI) and the image, is structured in a series of steps that begin with the selection of the unit of analysis followed by the definition the SD evaluation criteria and the indicators for each. Subsequently, the types of relationships with the system indicators were defined, and relativization functions applied to indicators. Finally, the partial indices (for each criterion) and the final index (SDI) were estimated. Then it is referring to each step.

The relative importance (or weight) of the dimensions (E, S, A, I) was calculated using a simple matrix containing the opinion of local producers. For this, the question arose: "Which of these dimensions (S, E, A, I) considered most important for assessing whether a project would impact positively (would be sustainable) in the area? (1-100 score of importance)". It is noteworthy that although the systems function as a unit, however, this division (dimensions) is useful for didactical purposes.

The criteria are those aspects that are included in each dimension and are best able to explain it (Sepulveda, 2008). These criteria were identified from the observation of the reality of the area, as well, interviews with local actors. Those aspects that could improve or worsen the "level" of SD in the area, regardless of whether they were related or unrelated energy themes were considered. For each criterion, indicators were defined, being these qualitative or quantitative variables that can be measured, and allow time to test the trend of system sustainability. Indicators become the basis of image estimation system. In this case, in order to achieve certain equilibrium, eight indicators for each of the dimensions defined. Once defined indicators, the type of relationship that each indicator had with the general environment ( + or -$)$ was specified. That is, increasing the value of the indicator may reflect better or worse for the criterion considered. If an increase in the value of the indicator could result in an improvement of the system, it was considered that the relationship was positive $(+)$. Conversely, if an increase in the value of the indicator could worsen the situation, an inverse relationship was considered $(-)$.

In order to adapt the indicators to a common scale, a relativisation function was used, which is based on the methodology proposed by the UNDP (United Nations 
Development Program) to calculate the Human Development Index (Sepúlveda, 2008). Individual indices were obtained which range from 0 to 1 . In both cases (positive or negative relationship), a value of 1 represents a better situation, contrary to a value of 0 , in which case represents the situation worse. The standardization allows relativize all indicators and therefore generate a new set of data suitable for comparative analysis. Four sub-indices (AI, SI II and EI) were obtained. Each of these indices were weighted by the average value assigned to each dimension and then averaged to obtain the final SDI. The value of the dimensions was obtained from the initial survey (stakeholders). Partial index obtained for each of the dimensions, were then represented in a multidimensional diagram. When the SDI was equivalent to a value below 0.2 , it was classified "collapse"; between 0.2 and 0.4 as "critical"; from 0.6 to 0.8 as "stable" and from 0.8 to 1 was the "optimum" situation of the system.

\section{Results}

\subsection{Stakeholders sustainability perception}

The stakeholders local provided a rich overview of their perspective of what they considered a more sustainable situation that the current reality lived (Table 1). In most cases, perceptions were limited to aspects of structural type, which could be reversed with relative facility, prioritizing economy aspects. In another set of views, shows aspects of environmental care, unable to define clearly in many cases, how they should be preserved or handled Valley resources. And finally, the group of people with a higher level of education or information, which defined the concept of the way it has spread and popularized, pointing to and including aspects of social (justice, participation, respect).These groups were organized only for the purpose of gaining a better understanding and inclusion of the answers given by the people, and seeking to detect the main lines of argument. Mostly, perceptions are focused on problems that the people face daily.

\begin{tabular}{ll}
\hline Dimension & A more sustainable situation for the Valley would be one where there is/are.. \\
\hline Economical & "Better provision, better infrastructure, and better distribution of water." \\
& "Better roads and access routes for the movement of production or inputs." \\
& "Development of local markets." \\
& "Less monopolization by tobacco companies". \\
& "Greater government support with training and technical advice". \\
& "Better income for producers supported by long-term policies." \\
& "More information for all sectors alike." \\
Environmental & "Water available in quantity and quality for all." \\
& "Soils do not deteriorate." \\
& "Proper management of natural resources, to enable the development of \\
& productive activities". \\
& "Less deforestation, since forest provide food, firewood and different \\
& services". \\
& "Greater use of renewable energy." \\
& "Coverage of basic social services for all". \\
& Correct treatment of waste, to prevent contamination of air, soil and water"
\end{tabular}




"Dissemination and use of clean technologies."
"More diversified productive activities".
"People who appreciate the place where it belongs, and takes care of the
natural environment".
"Political decisions in consultation with the local population and respect and
incorporate the views in decision-making".
"Respect for land ownership rights and regularization the property titles to
ancestral owners.
"Regularization of jobs and compliance with laws and regulations"
"Salaries that cover basic needs of families."
"More housing credits for families".
"Young people that have more opportunities to study and work locally".
"No weapons, and there is more control and security".
"Politicians who keep their promises".
"Proposals for young people away from drugs and alcohol."
"Better equipping health centers, and medical coverage."

Table 1. Some ideas of sustainability, expressed by local stakeholders consulted.

Clearly, the sustainability condition has to do with those aspects that are currently perceived as unsustainable or negative, for stakeholders. The overview of the different stakeholders on the assessment of the dimensions is shown in Figure 1. The population recognizes the economic dimension as the one with the most weight (36\%), followed by the social and environmental (25\% in each case) and lastly, the institutional dimension $(14 \%)$. In the opinion of the inhabitants, the economical aspect is a priority in the sustainability of an initiative in the region because it is the local people's main interest. This prioritization has been recognized on a global level as typical among the developing regions and third world countries (Gnansounou et al., 2008).

In an analysis broken down into different opinions, one can see that the companies define their projects granting the highest importance to the economic and environmental aspects, which makes sense in the requirements of the current legal environmental frame and in the search of maximizing the profits. The governments spread their interest scale between environmental, social and institutional aspects. The town people and local producers give most importance to the economical (technological specifically) and social areas, pointing out the impediment the technology imposes in many experiences and the need to ensure their job and income resource. The associations define their decisive axis as the economic and technological facets, similar to the producer, which makes sense because in most cases, the producers make the associations. A balance of opinions is therefore necessary to achieve a consensus definition of the conditions that can ensure sustainable use of bioenergy in a particular region (Begic and Afgan, 2007). 


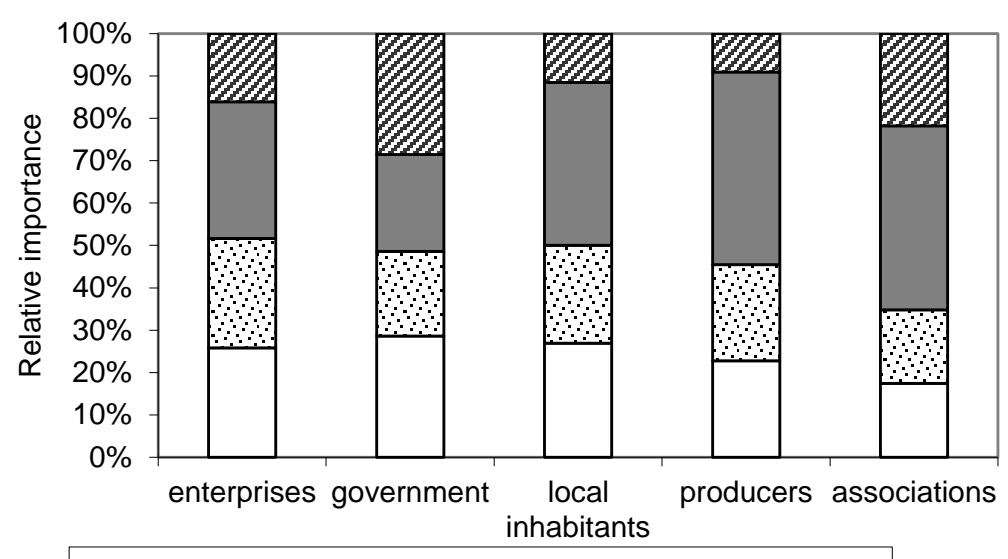

口environmental घsocial 口economical छinstitutional

Figure 1.Sustainability dimension importance from the point of view of five different sectors.

\subsection{Criteria and indicators assessment}

In most cases, we sought to measure each criterion by indicators directly related to the evaluation of the responses of the population sample taken. In the environmental dimension, aspects of natural resource management (A1, A2, A3, A6) and impact of human practices (A3, A4), were included. Indirectly it sought to assess the level of GHG emissions, mainly $\mathrm{CO}_{2}$ from registration of fossil fuel use (A5). Moreover, pollution in different phases (water, soil, air, vegetation) were analyzed using A1 (impact of landfills to open sky, and sometimes burning) and A7 (impact by spraying and alteration of chains trophic, generation of resistant populations pesticides, etc.). The A1 was also used to assess the level of waste management area. The planning and implementation of strategies for resource management may be noted from A2, A3, A4 and A6, as well the level of appreciation of the natural environment (A8). Regarding energy issues, the indicator is used specifically A5. About social dimension, living conditions and equity (S1, S2, S3, S4, S5 and S7), social justice (S1, S6) and public acceptability and appropriation of bioenergy projects (measured as participation in such projects) (S8) were considered. Directly latter is notoriously shocked when people show interest and willingness to participate in the proposed projects.

In the institutional and organizational aspects, the $\mathrm{I} 7$ indicator was calculated based on interviews with municipal leaders in each case. A total number of 11 municipalities that could potentially participate in bioenergy projects were considered. It interested to know the level of local participation in the defense of private or public interests (I3) and the level of organization and willingness to collective enterprises (I1, I5, I8). Aspects that would ensure the continuity of the projects were detected from confidence in the leadership of turn (I2, I6), as well involvement with political projects (I4). Strengths and weaknesses are highlighted and allow comprehensive work and future lines to improve the region. As regard as economic dimension, the indicators allowed relieve the level of 
economic solvency (E1, E2), its capitalization (E5, E6), the level of strength of the rural economy (E3, E4, E7), and energy dependence fossil fuels from the investment to be made in each production cycle in this issue(E8) (see Manrique y Franco, 2013).

\subsection{Starting point image}

There are large imbalances between each of the dimensions and within each, and especially environmental aspect is long overdue. The contributions of each of the dimensions are shown in the Figure 2 and allow identify the most critical variables being analyzed for each dimension.

A1

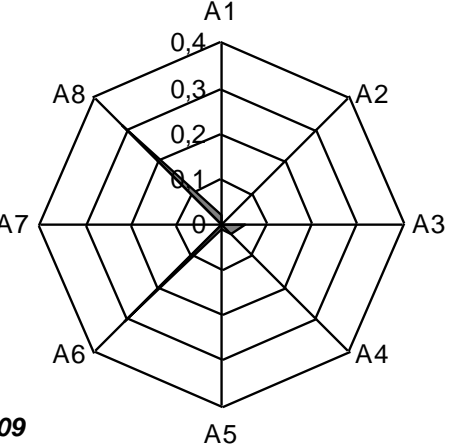

(a) Environmental: collapse

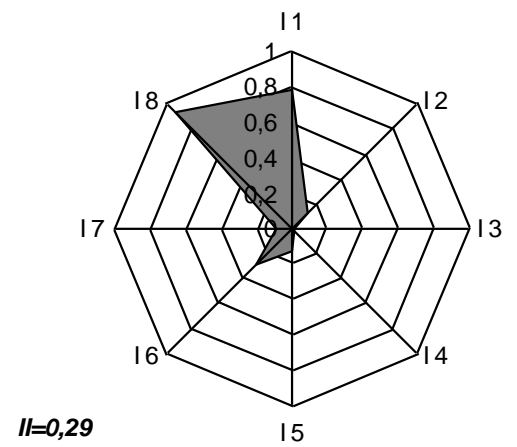

(c) Institutional-organizational:critical

Figure 2.System response for each dimension considered.
$I S=0,21$

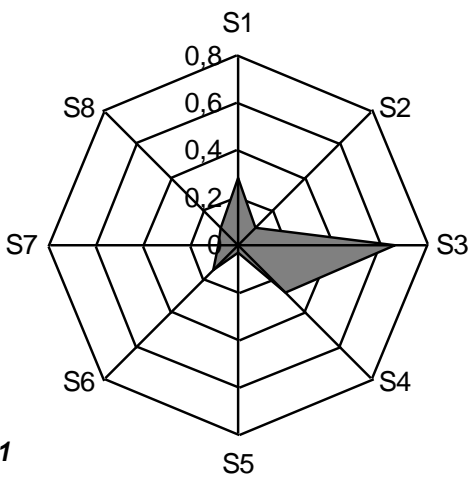

(b) Social : critical

IE $=0,25$

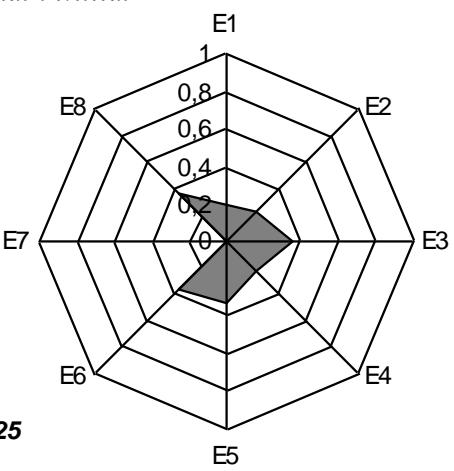

(d) Economical-productive: critical

As it is clearly observed, any used indicator related to the environment shows very low values, implying weak management of the resources and protection of the environment. The level of environmental consciousness is low, although there are some possible recognizable damages due to human activities, there is no will nor decisions to seek possible solutions. Socially, one can observe large structural deficiencies of income distribution, education and health, which must be taken into account in first place. Although there is a great enthusiasm in the participation of bioenergy projects, these projects must be approached for resolving the basic demands. Regarding the institutional-organizational, there are some strengths in the system that must be observed, the producers getting together for the irrigation associations, tobacco societies 
and cooperatives, local producers associations, all of which gather the community to realize common efforts towards the objects of their interest. In this case, it could be very important for the viability of the implementation of the bioenergy systems although the trust and communication with the leadership must be reinforced. Economically and productively, there is a strong dependency on subsidies and financing mechanisms which could point to a weak economy. The local capitalization levels are very low and there are large discrepancies with the income, deficiencies in the productive infrastructures and a high social unconformity. This analysis allows for a visualization of the problems and system unbalances in just one image, and therefore point towards the dimensions and variables which require the implementation of corrective policies and tools. The total value of sustainability measured by SDI (average partial indexes) was 0.218 , so the current situation of the system can be defined as "critical".

\subsection{Potential future image}

The initial diagnosis of the Valle's situation in their level of sustainability can be improved by applying bioenergy alternatives identified, bringing the values of the indices previously estimated, as shown in detail in Figure 3.In an overview, bioenergy projects provide to the Valley a better situation (more sustainable) and could raise the SDI to 0.410 , which means a situation almost twice as good as the current. Much of the indicators considered are affected to a greater or lesser extent by the implementation of bioenergy projects. But there are other aspects related to structural deficiencies, requiring more complex and comprehensive political decisions. For example, only $12 \%$ the inhabitants of the sample had social security coverage; $37 \%$ of cases, producers employ family labor; only $17 \%$ said they have employees or laborers hired in rule; $40 \%$ of the surveyed population has no education or only reached primary level (of which 67\% did not complete the studies), etc.

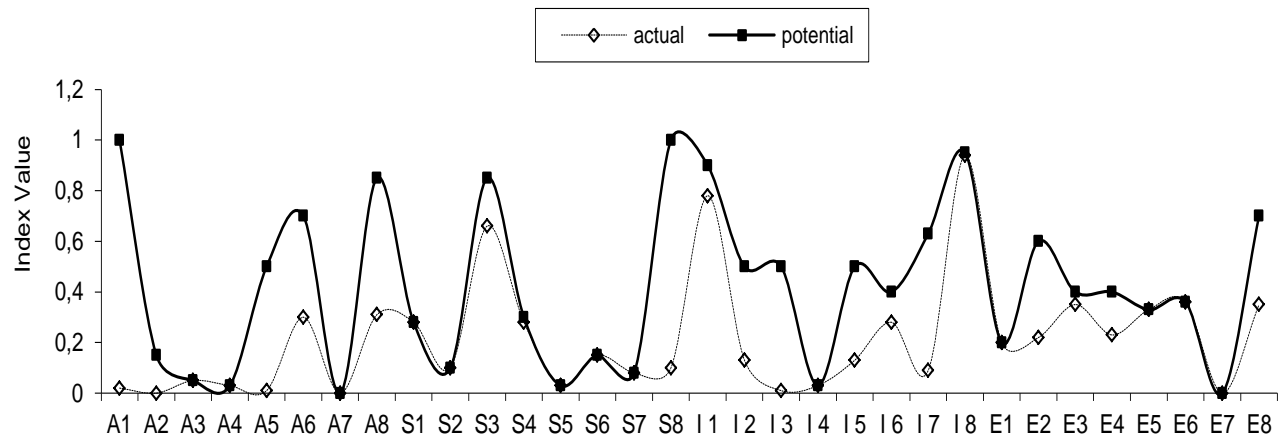

Figure 3.Current and potential status of the Lerma V alley due to bioenergy projects implementation.

It may be noted that the biggest change occurs in the environmental dimension (IA), which amounts to 0.37 giving the character "critical", although higher than previous state (Figure 4 a, b, c, d). The II (institutional index) is changed largely, with a value of 0.56 which puts it in an "unstable" situation, but higher than the previous. The biggest impacts are in the areas that have to do with the "organizational" aspect rather than the "institutional", as proposed projects involve trade and interconnections that may be 
favorable in other ways for producers. This is an almost intrinsic aspect of bioenergy projects, to the extent that their dispersion characteristics, low energy density, seasonality, typical of biomass resources, promote regional rather than local measures. The proposed use of biomass resources not currently used, can contribute significantly to the conservation of natural capital (A4, A6, A8), reduced $\mathrm{CO}_{2}$ emissions (sustainable use of biomass is neutral in emissions of $\mathrm{CO}_{2}$ ), improved hygiene and sanitation aspects of environmental (solid waste disposal at the regional landfill, reducing impacts and pollution), as well presently wasted energy recovery. This also would impact on energy prices from fossil fuel consumption, with a level of cost savings, and could help solve some basic unmet demands: continuous supply of fuel for cooking and heating, most households connected to the grid, providing good public sites (schools, hospitals, small rooms, etc.), among others.

$I A=0,37$

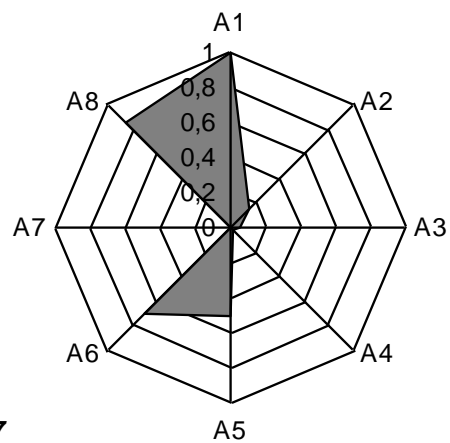

(a) Environmental: critical

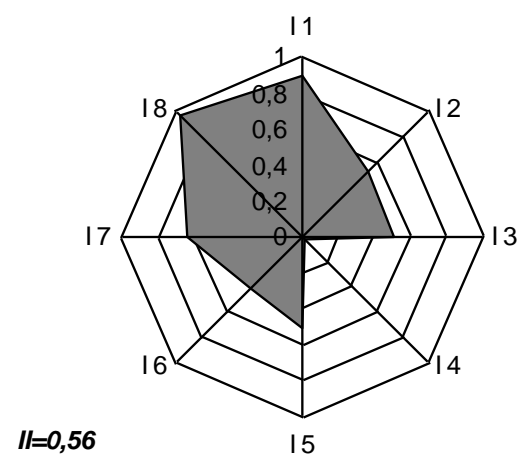

(c) Institutional-organizational: unstable

Figure 4.Potential situation of Lerma Valley because bioenergy systems.
IS $=0,35$

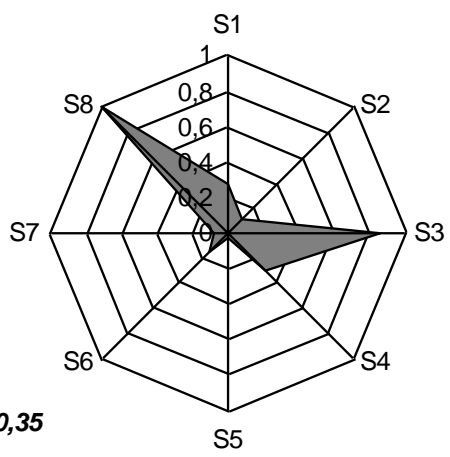

(b) Social: critical

$I E=0,37$

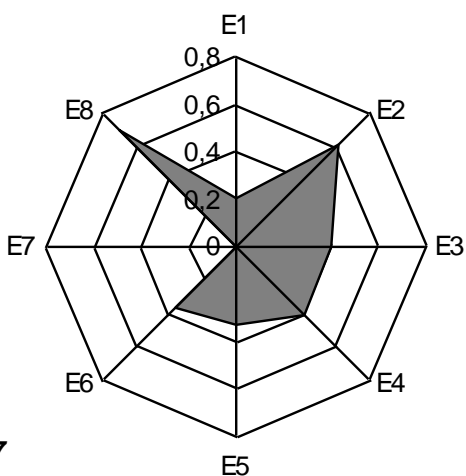

E5

Planned and executed properly, could involve stable jobs. Regionally, the logistics of using biomass requires a certain level of organization and distribution of tasks, and management needs the support of local leadership and cooperation agreements. Regulations, financing and other issues must be resolved this level to give strength to the initiatives. While the local population does not consider as important institutional 
aspects, these can result in real bottlenecks for these projects. Moreover, the option for certain types of technology applications at the expense of others, will be needed to accompany the successful development of bioenergy: improved and more efficient stoves, lower emissions technologies and local or national provenance, use of boiler more efficient in production cycles, among others. There is a lot of work to be done, but the path is made by walking.

\section{Conclusion}

In our experience, working with local people was very enriching and is absolutely necessary. Correct identification of the starting situation and the desirable future state (high sustainability) proposed by the inhabitants, is critical to achieving real local development. In this case, although bioenergy appear as a sustainable energy option to fossil fuels, when these projects want to be implemented in developing regions that have many structural shortcomings (lack of titles to land, lack of access to services modern as electricity or sanitation, lack of road infrastructure, poverty and lack of employment alternatives, etc.), only achieved a level of superficial impact, although a positive one (depending of course, the system and its characteristics).

Anyway, the framework of analysis and the proposed methodology allow the conclusion about the benefits of bioenergy projects in the area. The failings and the imbalances of the system are clearly identified, and therefore, allow focus towards the dimensions and variables that need to implement policies and corrective instruments. Since the methodology used is fully dynamic, if the study sample is extended or if must be analyzed the same system over time, this is perfectly feasible to be done. But even more, this methodology can also be used to analyze other social development projects, only redefining the criteria and indicators to be measured.

\section{References}

Begic, F. and Afgan, N.H. (2007).Sustainability assessment tool for the decision making in selection of energy system-Bosnian case. Energy 32, 1979-1985.

Bossel, H. (1999). Indicators for Sustainable Development: theory, method, applications. IISD Publications Centre.124 p, ISBN 1-895536-13-8.

Buchholz, T., Rametsteiner, E., Volk T.A. and Luzadis, V.A. (2009). Multi Criteria Analysis for bioenergy systems assessments. Energy Policy 37, 484-495.

George, C. (1999). Testing for sustainable development through environmental assessment. Environmental Impact Assessment Review 19, 175-200.

Gnansounou, E., Panichelli, L. and Villegas, J.D. (2008).Sustainable liquid biofuels development fortransport, working paper, LASEN, Ref.437.103.EPFL http://bpe.epfl.ch.

Holden, E. and Linnerud, K. (2007). The Sustainable Development Area: satisfying basic needs and safeguarding ecological sustainability. Sustainable Development 15, 174-187.

Kemmler, A. and Spreng, D. (2007).Energy indicators for tracking sustainability in developing countries.Energy Policy 35, 2466-2480.

Lumley, S. y Armstrong, P. (2004).Some of the Nineteenth Century Origins of the Sustainability Concept. Environment, Development and Sustainability 6, 367-378. 
Manrique, S.; Franco, J. y Núñez, V. (2014). Biomass feedstock availability for the supply of bioenergy in Lerma Valley (Salta, Argentina): an evaluation for energy territorial planning. American Journal of Biomass and Bioenergy 3 (1), 34-57.

Manrique, S.M. y Franco, A.J. (2013).Assessing the Sustainability of Bioenergy Systems. In: Bioenergy Systems, Biological Sources and Environmental Impact. Ed. Michel C. Allard. Nova Science Publishers, Pages 1-40.

May, J.R. and Brennan, D.J. (2006).Sustainability assessment of Australian electricity generation. Process Safety and Environmental Protection, 84(B2), 131-142.

Mog, J.M. (2004). Struggling with sustainability - a comparative framework for evaluating sustainable development programs. World Development 32 (12), 2139-2160.

Takada, M., Morris, E. and Rajan, S.C. (2000).Sustainable Energy Strategies. Materials for decision makers.UNDP.Initiative for Sustainable Energy (UNISE).

Tijmes, P. and Luijf, R. (1995).The Sustainability of our Common. Future: An Inquiry into the Foundations of an Ideology. Technology in Society 17 (3), 327-336.

WCED (World Commission on Environment and Development).(1987). Our Common Future. Oxford: Oxford University Press. 